\title{
Thromboembolic events as an emerging adverse effect during high-dose intravenous immunoglobulin therapy in elderly patients: a case report and discussion of the relevant literature
}

Published online: 4 March 2005

(C) Springer-Verlag 2005

\section{Ann Hematol (2004) 83:661-665}

Due to a technical error, the reference list was rendered incorrectly. It is now correct as presented below. The entire article is reprinted, so that the reader can move from the reference citations in the text to the corrected reference list.

\section{Introduction}

The therapeutic indications for intravenous immunoglobulin (IVIg) have increased significantly in the last years. It is currently FDA approved for the treatment of primary humoral immunodeficiency syndromes, idiopathic thrombocytopenic purpura (ITP), preventively after bone marrow transplantation, in B-cell chronic lymphocytic leukemia, in pediatric HIV infection and Kawasaki syndrome [1]. However, it is also being used in at least 53 off-label conditions [2], with various strengths of evidence supporting its use. The listed adverse reactions include anaphylactic reactions (especially in patients with selective IgA deficiency), aseptic meningitis syndrome, acute renal failure, headaches, fatigue, chills, backache, leg cramps, lightheadedness, fever, urticaria, flushing, slight elevation of blood pressure, nausea and vomiting, and local pain and irritation at the infusion site [1]. Reviews on the topic of possible adverse effects

The online version of the original article can be found at http://dx. doi.org/10.1007/s00277-004-0895-2

\section{Hefer $(\square)$}

Department of Internal Medicine,

St. Luke's/Roosevelt Hospital Center,

1000 Tenth Avenue,

New York, NY 10019, USA

e-mail: hefer.david@earthlink.net

Tel.: +1-212-5235678

\section{Jaloudi}

Division of Hematology/Oncology, Department of Internal

Medicine, St. Luke's/Roosevelt Hospital Center,

Columbia University College of Physicians \& Surgeons,

1000 Tenth Avenue,

New York, NY 10019, USA also mention liver enzyme abnormalities, immune complex arthritis, hypersensitivity myocarditis, neutropenia, hypotension, encephalopathy, alopecia, uveitis, hypothermia [3], as well as acute hemolytic reactions [4], and the hyperviscosity syndrome [5]. Furthermore, there is a low but definitive risk that the final product can be virally contaminated with HIV, HBV, or HCV [2]. A case of transmission of parvovirus B19 has been reported [6].

There have been several cases of thromboembolic events reported in the world literature that occurred either during or in short temporal relation to IVIg infusion. Some reviews $[3,4,7-9]$ mention this serious side effect; others $[5,10]$ do not. Our recent experience with a patient suffering a large anterior wall myocardial infarction while receiving IVIg therapy prompted us to review the current literature and to discuss possible causes and treatment options.

\section{Case presentation}

An 82-year-old man with a past medical history significant for hypertension, benign prostatic hyperplasia, and chronic myelogenous leukemia diagnosed 4 months earlier and complicated by refractory immune thrombocytopenia was admitted to our institution for active bleeding and thrombocytopenia. During the admission he received platelet and blood transfusions as well as a trial of IVIg therapy. He had had two significant episodes of spontaneous bleeding within the last 4 months - one episode of spontaneous gross hematuria requiring transfusions and one episode of a spontaneous subdural hemorrhage which required neurosurgical drainage. He also had had an episode of paroxysmal atrial fibrillation 1 month earlier, which was attributed to a trial of interleukin 11 . He was taking prednisone $20 \mathrm{mg}$ daily, metoprolol $50 \mathrm{mg}$ daily, imatinib mesylate $400 \mathrm{mg}$ daily, and doxazosin $2 \mathrm{mg}$ daily. The physical exam on admission was significant for numerous chronic ecchymoses on the trunk, and both arms and legs, as well as a left subconjunctival hemorrhage and a right periorbital hematoma which had developed 2 days prior to admission. He also had a palpable spleen, and his liver was palpable $2 \mathrm{~cm}$ below the costal 
margin. His laboratory values on admission were significant for a BUN of 55, creatinine of 1.4, glucose of 184, and a calcium of 8.2. His white count was 24,200 (differential $49 \%$ neutrophils, $13 \%$ lymphocytes, $15 \%$ monocytes, $8 \%$ bands, $6 \%$ metamyelocytes, $7 \%$ myelocytes, and $2 \%$ atypical lymphocytes), hemoglobin 8.7 , hematocrit $25.4 \%$, and platelet count 21,000 . His electrocardiogram on admission showed a normal sinus rhythm at 62 beats per minute, axis and intervals were within normal limits and there were no ST-segment or T-wave changes.

He received a total of $37.5 \mathrm{~g}$ of IVIg $(10 \%$ Venoglobulin, Alpha Therapeutic, at a rate of $1 \mathrm{mg} / \mathrm{kg} / \mathrm{min}$ ) as well as one platelet transfusion on the 1st hospital day. A total of $65 \mathrm{~g}$ of IVIg (10\% Venoglobulin, Alpha Therapeutic, at a rate of $1 \mathrm{mg} / \mathrm{kg} / \mathrm{min}$ ) was given on the $2 \mathrm{nd}$ hospital day prior to a transfusion of packed red blood cells.

About 20 min after starting the blood transfusion and about $3 \mathrm{~h}$ after finishing the infusion of IVIg, he began complaining about sudden onset substernal chest pressure in an intensity of 5/10 with radiation to the back. The transfusion was stopped and an initial electrocardiogram showed hyperacute T waves in V3, V4, and V5. Serial electrocardiograms then showed further peaking and ST-segment elevations in V2-V5. An initial troponin was 0.2 with a total CPK of less than 20; however, a second troponin obtained $4 \mathrm{~h}$ later showed a troponin of 14.8 and a total CPK of 163 . He was started on 21 oxygen via nasal canula, and one sublingual nitroglycerin and $2 \mathrm{mg}$ of morphine i.v. were given. The patient was free of chest pressure after the above treatments. No aspirin, heparin, or lytic agents were administered, and also primary PTCA was not attempted because of concern for bleeding complications.

An electrocardiogram obtained $6 \mathrm{~h}$ after the onset of chest pressure showed complete resolution of the ischemic changes with no more evidence of peaked T waves or ST-segment elevations, consistent with spontaneous reperfusion of the infarct-related artery. An echocardiographic exam the next day showed a normal ejection fraction and no abnormalities except a dilated left atrium. The patient was discharged home 2 days after the event and has had no further episodes of myocardial infarction or ischemia. He underwent one more course of IVIg 4 weeks later, which was uneventful but did not improve his platelet count. The patient remained thrombocytopenic and was requiring episodic platelet transfusions. He died 9 month after the above event from a spontaneous intracerebral hemorrhage.

\section{Discussion}

After a careful search of the world literature we found a total of 29 reported cases in which thromboembolic events occurred in a close temporal relationship to IVIg therapy (Table 1).

There are four more reports of thromboembolic events in patients with ITP treated with IVIg; however, a clear-cut temporary association to the IVIg treatment cannot be established from the report [11-14]. An abstract on a retrospective study [15] found a total of 16 thromboembolic events in 295 patients who received IVIg, however the com- plete data has never been published. Most studies evaluating the side effects of IVIg have studied younger populations, with an inherent lower risk of developing thromboembolic complications, and therefore this side effect might not have been observed $[16,17]$. Studies focusing on the use of IVIg in older patients generally do not have enough patients to show the true incidence of these serious side effects [18-21]. Two larger studies focusing on the use of IVIg in older patients reported one thromboembolic event in 81 patients [22] and one in 56 patients [23]. Several reviews about the use of IVIg mention thromboembolic side effects but most cite only a few cases and list these as rare [7-9].

Several mechanisms have been proposed for the prothrombotic effect of IVIg:

a. IVIg could have platelet agonist activity as it enhances ATP release in vitro [24].

b. The plasma and blood viscosity both in vitro and in vivo are increased by IVIg, and this is demonstrated in the short term [25] as well as in the long term [26]. Elevated plasma viscosity was reported in one case of a thromboembolic event [27].

c. Treatment with IVIg may lead to alterations in the cytokine profile with a localized production of vasoconstrictive cytokines leading to thrombotic events [28].

d. IVIg may induce arterial vasospasm [29, 30].

e. It has been shown that IVIg may be contaminated with activated coagulation factor XI [31].

f. An immunologic immunoglobulin-induced cerebral vasculitis has been suspected in some cases of cerebral infarction related to IVIg therapy $[29,30]$.

There have been very few reports focusing on the treatment of thromboembolic events associated with IVIg therapy, and these have mostly implicated standard therapeutic interventions with platelet inhibitory drugs, anticoagulation, and thrombolysis. In our reported case we opted for an extremely conservative approach in fear of the high bleeding risk of our patient, and the patient eventually spontaneously reperfused the infarct-related artery. If the underlying pathophysiologic event in thromboembolic events associated with IVIg therapy is rather a transient hyperviscosity syndrome and not a true thrombotic event, therapy should be rather aimed at reversing hyperviscosity and not using standard treatment approaches for thromboembolism. However, further basic and clinical research will be necessary to find the optimal therapeutic approach.

\section{Conclusion}

1. In the face of 30 (including our case) reported patients -10 of whom died - with serious thromboembolic complications while receiving IVIg therapy, we consider it necessary that physicians and manufacturers alike are aware of this rare but potentially fatal adverse effect and that they inform patients about it. From the known data, the risk seems to be especially high in elderly patients with previous thromboembolic events 
Table 1 Characteristics of 29 reported cases of thromboembolic events occurring at or near time of IVIg therapy. CAD coronary artery disease, $C I D P$ chronic inflammatory demyelinating poly- neuropathy, $D M$ diabetes mellitus, $D V T$ deep vein thrombosis, $H T N$ hypertension, ITP idiopathic thrombocytopenic purpura, $M I$ myocardial infarction, $N D$ not disclosed, $P E$ pulmonary embolism

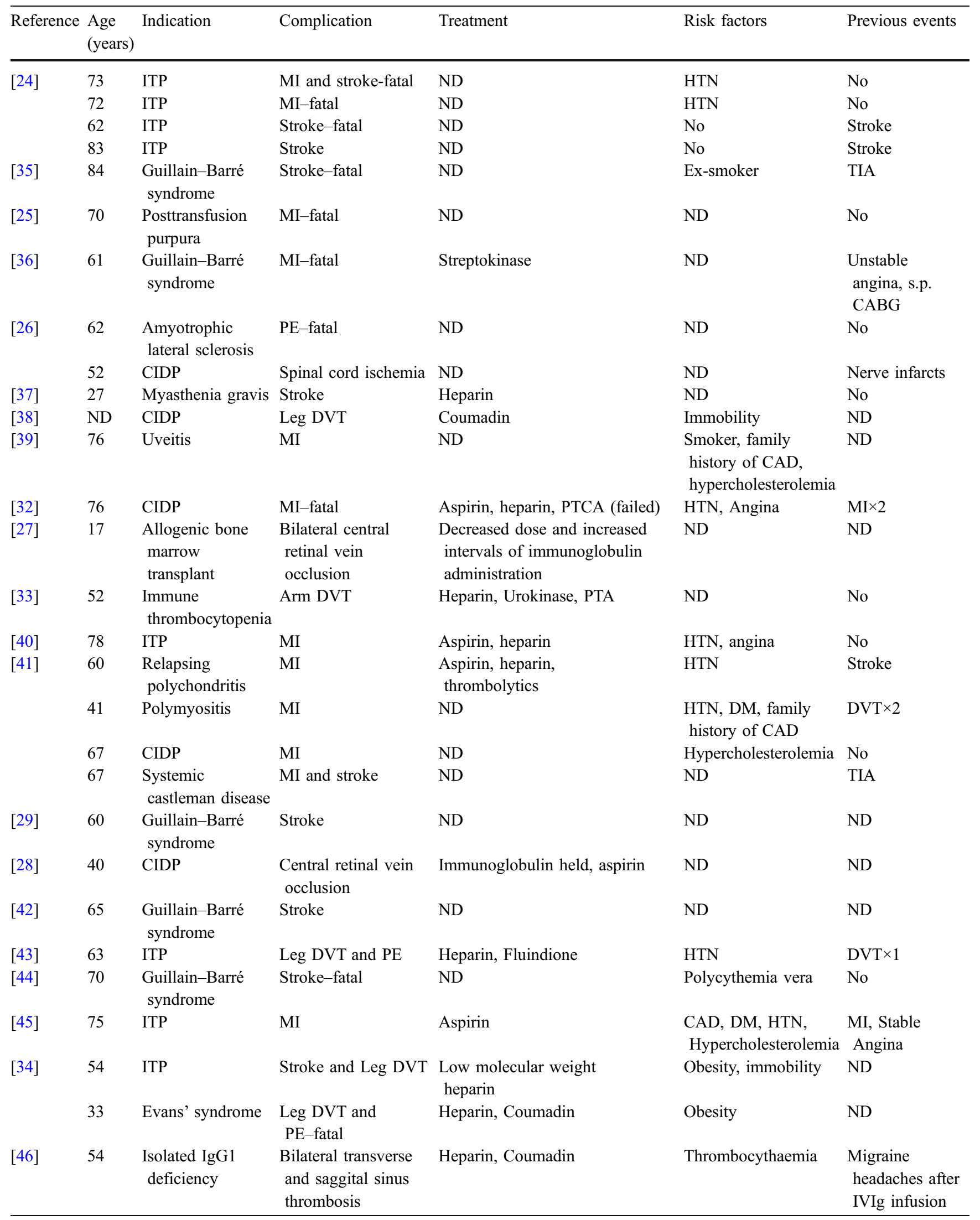


or cerebrovascular risk factors and also may be higher in patients with paraproteinemias.

2. It has been suggested that when IVIg therapy is administered to a patient with a high risk of thromboembolic events, this should be done in a well-monitored setting with careful attention to the development of any symptoms of thromboembolism [32], a baseline serum viscosity should be obtained if the patient has a concomitant paraproteinemia [26], the infusion rate should be slowed down, high-dose infusions should be avoided, and blood products should not be given concomitantly [33]. There is, however, currently no clinical evidence to indicate that the above measures are of any benefit. Some authors suggest lowering the dose in obese patients to prevent high intravascular concentrations, because of their relatively smaller intravascular volume [34].

3. The optimal treatment for acute myocardial infarction associated with IVIg therapy is not known. However, if the indication for IVIg therapy is immune thrombocytopenia, it may be safe to withhold antiplatelet therapy to avoid bleeding complications as spontaneous reperfusion can occur and also because platelet activation may not play the same role as in classic acute coronary syndromes.

\section{References}

1. Walsh PM (2003) Physicians' desk reference, 57th edn. Thompson, Montvale

2. Ratko TA, Burnett DA, Foulke GE et al (1995) Recommendations for off label use of intravenously administered immunoglobulin preparations. JAMA 273:1865-1870

3. Stangel M, Hartung HP, Marx P et al (1997) Review side effects of high-dose intravenous immunoglobulins. Clin Neuropharmacol 20(5):385-393

4. Misbah SA, Chapel HM (1993) Adverse effects of intravenous immunoglobulin. Drug Saf 9(4):254-262

5. Ryan ME, Webster ML, Statler JD (1996) Adverse effects of intravenous immunoglobulin therapy. Clin Pediatr (Phila) 35 (1):23-31

6. Hayakawa F, Imada K, Towatari M et al (2002) Life-threatening human parvovirus B19 infection transmitted by intravenous immune globulin. Br J Haematol 118:1187-1189

7. Stangel M, Hartung HP, Marx P et al (1998) Intravenous immunoglobulin treatment of neurological autoimmune diseases. J Neurol Sci 153:203-214

8. Martin TD (1999) Safety and tolerability of intravenous immunoglobulins. Electroencephalogr Clin Neurophysiol Suppl 50:514 520

9. Nydegger UE, Sturzenegger M (1999) Adverse effects of intravenous immunoglobulin therapy. Drug Saf 3:171-185

10. Kazatchkine MD, Kaveri SV (2001) Immunomodulation of autoimmune and inflammatory diseases with intravenous immune globulin. N Engl J Med 345:747-755

11. Otsuki T, Funakawa T, Sugihara T et al (1997) Multiple cerebral infarctions in a patient with refractory idiopathic thrombocytopenic purpura. J Intern Med 241:249-252

12. Fuchi T, Kondo T, Sase K et al (1999) Primary percutaneous transluminal coronary angioplasty performed for acute myocardial infarction in a patient with idiopathic thrombocytopenic purpura. Jpn Circ J 63:133-136

13. Koch CA, Archer TP, Kraut EH (1997) Myocardial ischemia in a patient with chronic refractory idiopathic thrombocytopenic purpura (letter). Arch Intern Med 157:2668
14. Fruchter O, Blich M, Jacob G (2002) Fatal acute myocardial infarction during severe thrombocytopenia in a patient with idiopathic thrombocytopenic purpura. Am J Med Sci 323(5):279280

15. Haplea SS, Farrar JT, Gibson GA et al (1997) Thromboembolic events associated with intravenous immunoglobulin therapy (abstract). Neurology 48:A54

16. Strasser-Fuchs S, Fazekas F, Deisenhammer F et al (2000) The Austrian Immunoglobulin in MS (AIMS) study: final analysis. Mult Scler 6[Suppl 2]:S9-S13

17. Poehlau D et al (2000) Treatment of chronic progressive multiple sclerosis with intravenous immunoglobulins - interim results on drug safety of an ongoing study. Mult Scler 6[Suppl 2]:S21-S23

18. Leger JM, Chassande B, Musset L et al (2001) Intravenous immunoglobulin therapy in multifocal motor neuropathy - a doubleblind, placebo-controlled study. Brain 124:145-153

19. Wolfe GI, Barohn RJ, Foster BM et al (2002) Randomized, controlled trial of intravenous immunoglobulin in mysthenia gravis. Muscle Nerve 26:549-552

20. Mendell JR, Barohn RJ, Freimer ML et al (2001) Randomized controlled trial of IVIg in untreated chronic inflammatory demyelinating polyradiculoneuropathy. Neurology 56:445-449

21. Jurlander J, Hartmann Geisler C, Hansen MM (1994) Treatment of hypogammaglobulinaemia in chronic lymphocytic leukaemia by low-dose intravenous gammaglobulin. Eur J Haematol $53: 114-118$

22. Cooperative group for the study of immunoglobulin in chronic lymphocytic leukemia (1988) Intravenous immunoglobulin for the prevention of infection in chronic lymphocytic leukemia- $\mathrm{a}$ randomized, controlled clinical trial. N Engl J Med 319:902907

23. Sherer Y, Levy Y, Langevitz P et al (2001) Adverse effects of intravenous immunoglobulin therapy in 56 patients with autoimmune diseases. Pharmacology 62:133-137

24. Woodruff RK, Grigg AP, Firkin FC, Smith IL (1986) Fatal thrombotic events during treatment of autoimmune thrombocytopenia with intravenous immunoglobulin in elderly patients (letter). Lancet 2:217-218

25. Reinhart WH, Berchtold PE (1992) Effect of high-dose intravenous immunoglobulin therapy on blood rheology. Lancet 339: 662-664

26. Dalakas MC (1994) High-dose intravenous immunoglobulin and serum viscosity: risk of precipitating thromboembolic events. Neurology 44:223-226

27. Oh KT, Boldt HC, Danis RP (1997) Iatrogenic central retinal vein occlusion and hyperviscosity associated with high-dose intravenous immunoglobulin administration. Am J Ophthalmol 124(3):416-418

28. Harkness KA, Goulding P (2000) Central retinal vein occlusion complicating treatment with intravenous immunoglobulin. Eye 14(Pt 4):662-663

29. Turner B, Wills AJ (2000) Cerebral infarction complicating intravenous immunoglobulin therapy in a patient with Miller Fisher syndrome. J Neurol Neurosurg Psychiatry 68:790-791

30. Mathy I, Gille M, Van Raemdonck F et al (1998) Neurological complications of intravenous immunoglobulin (IVIg) therapy: an illustrative case of acute encephalopathy following IVIg therapy and a review of the literature. Acta Neurol Belg 98:347351

31. Wolberg AS, Kon RH, Monroe DM et al (2000) Coagulation factor $\mathrm{XI}$ is a contaminant in intravenous immunoglobulin preparations. Am J Hematol 65:30-34

32. Fisman DN, Smilovitch M (1997) Intravenous immunoglobulin, blood viscosity and myocardial infarction. Can J Cardiol 13 (8):775-777

33. Go RS, Call TG (2000) Deep venous thrombosis of the arm after intravenous immunoglobulin infusion: case report and literature review of intravenous immunoglobulin-related thrombotic complications. Mayo Clin Proc 75:83-85

34. Emerson GG, Herndon CN, Sreih AG (2002) Thrombotic complications after intravenous immunoglobulin therapy in two patients. Pharmacotherapy 22(12):1638-1641 
35. Silbert PL, Knezevic WV, Bridge DT (1992) Cerebral infarction complicating intravenous immunoglobulin therapy for polyneuritis cranialis. Neurology 42:257-258

36. Ropper AH, Adelman L (1992) Early Guillain-Barré syndrome without inflammation. Arch Neurol 49:979-981

37. Steg RE, Lefkowitz DM (1994) Cerebral infarction following intravenous immunoglobulin therapy for myasthenia gravis. Neurology 44:1180-1181

38. Brannagan TH III, Nagle KJ, Lange DJ, Rowland LP (1996) Complications of intravenous immune globulin treatment in neurologic disease. Neurology 47:674-677

39. Rosenbaum JT (1997) Myocardial infarction as a complication of immunoglobulin therapy (letter). Arthritis Rheum 40(9):17321733

40. Paolini R, Fabris F, Cella G (2000) Acute myocardial infarction during treatment with intravenous immunoglobulin for idiopathic thrombocytopenic purpura (ITP) (letter). Am J Hematol 65(2): $177-178$

41. Elkayam O, Paran D, Milo R et al (2000) Acute myocardial infarction associated with high dose intravenous immunoglobulin infusion for autoimmune disorders: astudy of four cases. Ann Rheum Dis 59:77-80
42. Steinberger B, Coleman TA (2001) Multiple complications of IVIg therapy in a patient with Guillain-Barré syndrome. Am J Hematol 67(1):59

43. Alliot C, Rapin JP, Besson M et al (2001) Pulmonary embolism after intravenous immunoglobulin. J R Soc Med 94:187-188

44. Byrne NP, Henry JC, Herrmann DN et al (2002) Neuropathologic findings in a Guillain-Barré patient with strokes after IVIg therapy. Neurology 59:458-461

45. Crouch ED, Watson LE (2002) Intravenous immunoglobulinrelated acute coronary syndrome and coronary angiography in idiopathic thrombocytopenic purpura: a case report and literature review. Angiology 53:113-117

46. Evangelou N, Littlewood T, Anslow P et al (2003) Transverse sinus thrombosis and IVIg treatment: a case report and discussion of risk-benefit assessment for immunoglobulin treatment. J Clin Pathol 56:308-309 